\title{
Continuous Assessment, Mock Results and Gender as Predictors of Academic Performance of Chemistry Students in WASSCE and NECO Examinations in Ekiti State
}

\author{
Adesoji Francis Adewumi ${ }^{1} \&$ Kenni Amoke Monisola ${ }^{2}$ \\ ${ }^{1}$ Department of Teacher Education, University of Ibadan, Oyo State, Nigeria \\ ${ }^{2}$ Department of Chemistry, College of Education, Ikere Ekiti, Ekiti State, Nigeria \\ Correspondence: Kenni Amoke Monisola, Department of Chemistry, College of Education, Ikere Ekiti, Ekiti \\ State, Nigeria. Tel: 234-805-315-8669. E-mail: kenniamoke@yahoo.com
}

Received: March 4, 2013

Accepted: March 18, 2013 Online Published: June 22, 2013

doi:10.5539/ies.v6n7p1

URL: http://dx.doi.org/10.5539/ies.v6n7p1

\begin{abstract}
Education is one of the fundamental and critical indices of development in a nation or an individual. The challenges post by our fast changing and dynamic world informed the need to constantly access the educational process so as to guarantee quality of educational assessment; several factors have been identified to be responsible for students' poor performance in chemistry at the secondary school level. One of these factors could be modes of assessment. This paper, therefore investigated Continuous Assessment, Mock results and gender as predictors of academic performance in WASSCE and NECO Examinations. The study adopted a survey research design of the ex-post facto type. The sample comprised 892 senior secondary school III drawn from the secondary schools in Ikere local government area of Ekiti state. Three research questions were answered in the study. Data were analysed using multiple regression statistic. The results showed that $41.3 \%$ of the total variance in chemistry students, performance in WASCE results is accounted for by mock results, continuous assessment and gender (adjusted $\mathrm{R}^{2}=0.413$ ). And $0.7 \%$ of the total variance in chemistry students, performance in NECO examination results is accounted for by three factors (continuous assessment, mock results and gender) $\left(\mathrm{R}^{2}\right.$ $=0.007 \%$ ). the three factors made significance relative contribution to chemistry students' academic performance in WASCE; continuous assessment $(\beta=0.282, \mathrm{p}=0.05<)$, mock results $(\beta=0.396, \mathrm{p}=<0.05)$ and gender $(\beta=0.078$, $\mathrm{P}=<0.05$ ) while the contribution to performance in NECO examination is not significance. Mock result made the greatest contributions to chemistry students academics performance in NECO $(\beta=0.070, p=<0.05)$ followed by continuous assessment $(\beta=0.066, \mathrm{P}=<0.05)$ and gender $(\beta=0.061, \mathrm{p}=<0.05)$. Gender has significant influence on chemistry students' academic performance in WASSCE $(\beta=0.078, p<0.05)$ while it has little or no influence on chemistry students' performance in NECO $(\beta=0.061, p<0.05)$. That is, the three variables could be used to predict chemistry students' academic performance. It is recommended among others that school authority should ensure that only students whose performance in continuous assessment and mock examination is encouraging are allowed to register for either WASSCE or NECO examinations. Also, both internal and external assessment should be done without gender bias.
\end{abstract}

Keywords: continuous assessment, mock results, gender, academic performance

\section{Introduction}

Science and technology play an important role in nation building and development (Abbas, 2007). The reason is that science can exert a dominant, if not decisive influence on the life of individual as well as on the developmental effort of a nation (Adesoji and Olatunbosun, 2008). Nigeria depends on what science, technology and mathematics could offer for her national economic empowerment and development (Ajewole, 2005). The relevance of science to national goals, aspirations and economy dictates, to a large extent, the huge commitment and support which most nations give to science and technological development (Olagunju, Adesoji, Iroegbu and Ige, 2003).

The universal recognition of the above submission is responsible for the prime position that has been accorded science and in particular, chemistry Worldwide. Within the context of science education, chemistry has been identified as a very important school subject and its importance in scientific and technological development of 
any nation has been widely reported. It was as a result of the recognition given to chemistry in the development of the individual and the nation that it is made a core-subject among the natural sciences and other science related courses in the Nigerian education system. Chemistry and indeed chemists are linked to everything on earth as aptly captured in a slogan; what on earth is not chemistry? Chemistry plays a pivotal role at engineering sustainable economic development and growth in any nation. Put succinctly, there is no aspect of human endeavour on natural phenomena that chemistry does not feature. It features prominently in the areas of oil and gas, agriculture, health, environment, solid minerals, textile, cosmetics, water supply and sanitation, crime detection, pulp and paper, waste management just name it (Zuru, 2009). Chemistry is the catalyst of sustainable national growth and development. Chemistry is offered at the senior secondary classes in order to help student learn important aspects of scientific concepts that would enable them live effectively in their immediate environment (jimoh, 2001). Despite the importance of chemistry and its education value which is relevant to the need of individual learner, economics and technological breakthrough of a nation and the effort of researchers to improve on its teaching and learning, the performance of students in the subjects is not still encouraging. This is manifested in the poor performance of students in chemistry in the West African senior school certificate examination results (see table 1 ).

Table 1. Performance of candidates in the senior secondary certificate examination (May/June in chemistry 2000. 2007)

\begin{tabular}{lllll}
\hline YEAR & TOTAL & PECENTAGE & PERCENTAGE & PERCENTAGE \\
\hline & & A1-C6 & PASS 7-8 & FAIL \\
2000 & 195,810 & 31.88 & 26.71 & 47.39 \\
2001 & 301,740 & 36.25 & 27.06 & 36.67 \\
2002 & 262,824 & 34.42 & 29.47 & 36.09 \\
2003 & 282,120 & 50.92 & 24.26 & 21.84 \\
2004 & 269,774 & 38.97 & 26.83 & 39.19 \\
2005 & 278,684 & 67.89 & 26.04 & 48.83 \\
2006 & 281,622 & 23.06 & 27.52 & 49.42 \\
2007 & 293,167 & 30.57 & 32.26 & 37.17
\end{tabular}

Source: WAEC Research and statistics unit, Lagos.

Table 1 above shows that the percentages passes at credit level and above varies between 23.06 and 38.97 in six out of the eight years with the exception of 2003 and 20005 when the percentage pass at credit level and above were 50.98 and 67.89 respectively. This shows that the level of performance is still not good enough. The poor achievement of student in chemistry has continued to be a major cause of concern to all, particularly those in the mainstream of chemical education in Nigeria (Oloruntegbe, 2000; Adesoji and Olatunbosun, 2008). Among the factors that have been identified to be responsible for poor achievement in chemistry are poor methods of instruction, teacher attitude (Agoro, 2002), laboratory inadequacy (Baja, 1999), poor science background (Adesoji, 1999) and non-availability of effective teaching and learning resources in classrooms (Agoro, 2002).

Despise these research effort on which of the factors could determine achievement of students in chemistry, the performance of students continue to be generally poor. This was what prompted the present study, which try to find out the extent to which continuous assessment, mock examination results and gender could predicts academics performance of students in chemistry.

Educational assessment has been identified to be an integral and inseparable part of a sound educational system. Assessment data forms the basis upon which vital educational decisions about teaching, leaning, educational programme and learning environment are made. Continuous assessment is a mechanism whereby the final score of a student in the cognitive, effective and psychomotor domains of leaning systematically takes accounts of all his/her performance during a period of schooling.

The penultimate examination at the secondary school level of education under the old educational programme of 6-3-2-3 system was named "mock Examination" because it was usually used to assess the likely performance of 
the students in the senior secondary certificate Examination. However, it was not used as part of the overall assessment of the student at the school certificate level. Since the introduction of the 6-3-3-4 system, the continuous assessment, in particular has been integrated as part of the overall SSCE results for each student (Adeyeye and Ilugbusi, 2000).

Ojerinde (2004) stressed the need to integrate the behaviour of school-based scores sent to examination bodies into the results of schools and also recalled that the Nigerian policy on Education stipulates the use of school-based scores as a component of certification. At the secondary school level, school-based assessment is given $30 \%$ in the certification process. While the $30 \%$ is believed to be too high in some quarters others believe that it is not sufficient.

Studies have shown that one of the variables affecting learning in general and science learning in particular is gender, it is necessary to investigate the interrelationship between gender and science learning. Research have revealed that women are not only under-represented in science, but their levels of academic achievement in science and technology are low compared to men (Ishaya,2003 and National science foundation, 2008).

In predicting academic performance, what a learner knows will play a large part in determining what sense they can make of new information. The extent of relevant previous knowledge is a major factor in determining the achievement of learners in a particular subject or course. Learners build their own knowledge in an idiosyncratic way, using past experience and existing knowledge to make sense of new information. Since no two learners have the same knowledge and experience, different learners deal with all new information in different ways (Adebayo, 2002). Peers and Johnston in Adeyemi (2003) argue that a prediction of a future examination result could be made on the bases of the results of an earlier examination. However, despise all these result research efforts to solve this problem, there still little or no improvement in the students' performance in chemistry. There is need to carry out a study with a view to determining which of the selected variables (mock examination, continuous assessment and gender) could be use to predict student academic performance in WAEC and NECO.

\section{Research Questions}

The following research questions were formulated and tested at $\mathrm{P}<0.05$ :

1a: What is the composite effect of the independent variables (continuous assessment, mock result and gender) on chemistry students' academic performance in WAEC?

$1 \mathrm{~b}$ : What is the composite effects of the independent variable (continuous assessment, mock result and gender) on chemistry student academic performance in NECO?

2a: What are the relative effects of each of the independent variables (continuous assessment, mock result and gender) on chemistry students' academics performance in WASCE?

2b: What are the relative effects of independent variables (Continuous Assessment, Mock Result and Gender) on chemistry students' performance in NECO?

3a: Which of the independent variable (Continuous Assessment, Mock Results and Gender) will predict academic performance of chemistry student in WASCE?

3b: Which of the independent variables (Continuous Assessment, Mock Result and Gender) will predict academic performance of chemistry students in NECO?

\section{Methodology}

The design was a descriptive survey of the ex-post facto research type in which there was no treatment and manipulation of independent variable. It involves the collection of data from records. The target population for the study were schools that registered students for 2004 to 2006 final year chemistry WAEC and NECO examinations in Ikere Local Government of Ekiti State, Nigeria. Eight hundred and ninety two (892) chemistry students, which were randomly selected from ten (10) secondary school from Local Government Area of Ekiti state, formed the sample. he researchers made personal contact with all the selected schools and collected the following:

(i) the copy of cumulative continuous assessment for three consecutive years (2004-2006) in chemistry; (ii) the 2004-2006 chemistry mock results and (iii) the 2004-2006 may/June SSCE computerized result sheets send to each school by WAEC and NECO.

\section{Results and Discussion}

The section presents the results obtained in the study in line with the three research question raised. 
Research question 1a: What is the composite effect of the independent variables (continuous assessment, mock result and gender) on chemistry students' academics performance in WAEC?

To provide answers to this research question, Tables 2 and 3 are presented and used.

Table 2. Summary regression and analysis of continuous assessment, mock result and gender on students' performance in WAEC in chemistry

\begin{tabular}{llll}
\hline $\mathrm{R}$ & $\mathrm{R}$ Square R & Adjusted R Square & $\begin{array}{l}\text { Std. Error of the } \\
\text { ESTIMATE }\end{array}$ \\
\hline 0.644 & 0.415 & 0.413 & 1.1732 \\
\hline
\end{tabular}

Table 2 shows that three variables (continuous assessment, mock result and gender) jointly correlate positively with performance in chemistry $(\mathrm{R}=0.644)$. This implies that the variables are quite relevant in explaining students' performance in chemistry to an appreciable extent. The table also shows adjusted $\mathrm{R}$ value of 0.413 which indicate that $41.3 \%$ of total variance in chemistry students' performance in WAEC examination accounted for by the three variables (CA, mock result and gender) when combined. The remaining $58.7 \%$ could be due to other factors or variable not investigated in this studies as well as residuals. The significance or otherwise of the $\mathrm{R}$ - value is tested in Table 3 .

Table 3. ANOVA Table for the regression of the continuous assessment, Mock results and gender on students' performance in WASCE in chemistry

\begin{tabular}{lclcll}
\hline MODEL & $\begin{array}{c}\text { Sum of } \\
\text { squares }\end{array}$ & df & Mean square & F & Sig \\
\hline REGRESSION & 867.389 & 3 & 289.130 & 210.049 & 000 \\
RESIDUAL & 1222.318 & 888 & 1.376 & & \\
TOTAL & 2089.707 & 891 & & & \\
\hline
\end{tabular}

Significant at $\mathrm{P}<0.05$.

Table 3 shows that the $R$ values of 0.644 is significant $(F=210.049, P<0.5)$. Hence, the $R$-value obtained is not due to chance. Therefore, it is found that there is a significant composite effect of the continuous assessment, mock results and gender on chemistry students' academics performance in WASCE.

Research Question 1b: What is the composite effects of the independent variable (continuous assessment, mock result and gender) on chemistry student academic performance in NECO?

Table 4. Summary of Regression Analysis of Continuous Assessment, Mock Result and Gender on students Performance in NECO

\begin{tabular}{llll}
\hline $\mathrm{R}$ & $\mathrm{R}$ Square (R) & Adjusted R Square & $\begin{array}{l}\text { Std. Error of the } \\
\text { Estimation }\end{array}$ \\
\hline 0.082 & 0.007 & 0.003 & 1.3595 \\
\hline
\end{tabular}

In table 4 the $\mathrm{R}$ - value of 082 shows that the three variables continuous assessment, mock result and gender taken together have a positive multiple correlation with chemistry students performance in NECO. This means that the three variables could explain student performance in NECO. Further the R square value of .007 implies that $0.7 \%$ of the total variance in students performance in NECO is due to the three factors. The remaining $99.3 \%$ is due to other factors not included in the study as well as residual. The significance or otherwise of the $\mathrm{R}$ - value is tested in table 5 . 
Table 5. ANOVA Table for the Regression of Continuous Assessment, Mock Result and Gender on Students performance in NECO

\begin{tabular}{|c|c|c|c|c|c|}
\hline Model & $\begin{array}{l}\text { Sum } \\
\text { Squares }\end{array}$ & of $\mathrm{df}$ & Mean square & $\mathrm{F}$ & Sig \\
\hline Regression & 89.522 & 3 & 3.174 & 1.717 & .162 \\
\hline Residual & 1400.950 & 758 & 1.848 & & \\
\hline Total & 1410.472 & 761 & & & \\
\hline
\end{tabular}

Table 5 shows that the composite effects of the three variable (Continuous Assessment, mock result and gender) on chemistry students academics performance in NECO as revealed in the R - value of 0.082 is not significant $(\mathrm{F}=1.717, \mathrm{P}<.0 .5)$. Thus, the adjusted $\mathrm{R}$ value of $0.3 \%$ is due to chance.

Research Question 2a: What are the relative effects of each of the independent variables (continuous assessment, mock result and gender) on chemistry students' academics performance in WASCE?

Table 6. Result effects of continuous assessment, Mock Results and Gender on students performance in WASCE in chemistry

\begin{tabular}{|c|c|c|c|c|c|c|}
\hline Factors & $\begin{array}{l}\text { Unstandardized } \\
\text { coefficients }\end{array}$ & & $\begin{array}{l}\text { Standardized } \\
\text { coefficients }\end{array}$ & Ranks & & Sig \\
\hline & B & Std. & Beta & & $\mathrm{T}$ & Sig \\
\hline Constant & -6.784 & .423 & & & -16.029 & .000 \\
\hline $\mathrm{CA}$ & 6.013 & .008 & .282 & 2 & 7.564 & .000 \\
\hline Mock & .110 & .010 & .396 & 1 & 10.570 & .000 \\
\hline Gender & -.239 & .080 & .078 & 3 & 3.005 & .003 \\
\hline
\end{tabular}

*Significant at $\mathrm{p}<.0 .5$.

Regression Equation $\mathrm{Y}=6.0 \mathrm{E}-02 \mathrm{X}+0.110 \mathrm{X}-0.239 \mathrm{X}$. Where, $\mathrm{Y}=$ performance in WASCE Chemistry; $\mathrm{X}=$ Continuous Assessment; $\mathrm{X}=$ Mock and $\mathrm{X}=$ Gender

Table 6 shows that out of the three variables, mock result had the greatest contribution $(\mathrm{B}=0.396 ; \mathrm{P}<.0 .5)$ followed by Continuous assessment $(\mathrm{B}=.282 ; \mathrm{P}<.0 .5)$. The third in the ranking is gender. Gender had a low but significant influence on chemistry student performance in WASCE. From this result, all the contribution made by each of the three factors are significant. Hence, they all contribute significantly towards the determination of students' performance in WASCE.

Research Question 2b: What are the relative effects of independent variables (Continuous Assessment, Mock Result and Gender) on chemistry students' performance in NECO?

Table 7. Relative effect Continuous Assessment, Mock Result and Gender on students' performance in NECO

\begin{tabular}{lllllll}
\hline Factors & $\begin{array}{l}\text { Unstandardized } \\
\text { Coefficients }\end{array}$ & & $\begin{array}{l}\text { Standardized } \\
\text { Coefficients }\end{array}$ & Rank & & Sig \\
\hline Constant & B & Std & Beta & & T & Sig \\
CA & -1.206 & .520 & & & 4283 & .000 \\
Mock & 1.678 & .010 & .066 & 2 & -1.256 & .210 \\
Gender & -.167 & .013 & .070 & 1 & 1.312 & .190 \\
& & .100 & .061 & 3 & -1.670 & 0.95 \\
\hline
\end{tabular}


Table 7 shows that mock result made a greatest contributions towards chemistry students academic performance in NECO $(\mathrm{B}=.070 ; \mathrm{P}<.05)$ followed by Continuous assessment $(\mathrm{B}=.066 ; \mathrm{t}=-1.256, \mathrm{P}<.05)$ while Gender with beta weigh of $061 ; \mathrm{p}<.05$ made the least influence in NECO. The three factors made contributions which are not significant towards chemistry student academic performance in NECO. This is contrary to what is obtained for that of WASCE in this study.

Research Question 3a: Which of the independent variable (Continuous Assessment, Mock Results and Gender) will predict academic performance of chemistry student in WASCE?

From table 6 each of the three variables could predict academic performance of chemistry students in WASCE. These include Continuous Assessment $(B=6.013 ; t=7.564)$ Mock result $(B=0.110 ; t=10.570)$ and Gender $(\mathrm{B}=-0.239 ; \mathrm{t}=3.005)$ each at $\mathrm{p}<.0 .5$.

Research Question 3b: Which of the independent variables (Continuous Assessment, Mock Result and Gender) will predict academic performance of chemistry students in NECO?

From table 7, none of the three factors could predict academic performance of chemistry students in NECO. CA $(\mathrm{B}=-1.206 ; \mathrm{t}=-1.256 ; \mathrm{p}<.05)$ mock result $(\mathrm{B}=1.678 ; \mathrm{t}=1.312 ; \mathrm{p}<.05)$ and gender $(\mathrm{B}=-0.167 ; \mathrm{t}=-1.670 ; \mathrm{p}<$. 05)

\section{Discussion}

The study reveal that $41.3 \%$ of the total variance in chemistry student performance in WASCE examination is accounted for by mock results, Continuous Assessment and Gender. This shows that the performance of chemistry students in WASCE depend largely on these factors. Indeed, the study has further established that each of the three factors (Continuous Assessment, Mock Results and Gender) could predict academic performance of chemistry students in WASCE to an appreciable extent. The results in table 5 and 6 further showed that mock results made a greatest contribution to chemistry students' performance in WASCE. Mock results with a $($ Beta $=0.396 ; \mathrm{p}<.05)$ could serve as a better pointer to academic performance of chemistry students in WASCE than continuous assessment $(B=0.282 ; p<.05)$ and $\operatorname{Gender}(B=0.078 ; p<05$ respectively). The finding in agree with those of (Adesoji, 1999 and Olajide, 2006).

The study has shown that $0.7 \%$ of the total variance in student performance in NECO examination result is accounted for by the three factors. Table 7 shows that none of the three factors could make a significant contributions toward chemistry students academic performance.

The results of the study has further shown that it is not all the three factors that predicted chemistry students academic performance in WASCE that predicted that of NECO. The predictive capability of Continuous Assessment, mock results and Gender on WASCE is higher than that of NECO. Mock results and gender could be used to predict chemistry students' performance in WASCE. This does not apply to NECO examinations results as Continuous assessment and gender recorded low predictive capacity on NECO results. The practical implication of this finding is that mock examination results could be used to predicts results of students in the secondary school certificate examination WASCE) in chemistry. Continuous assessment could only be used to predicts results of student in NECO. Gender has influence in chemistry student academic performance in WASCE while if has little or no influence in chemistry students academic performance in NECO. These findings are in agreement with those found by (Adesoji, 1999) that mock examination results could be uses to predict the performance of students in the senior secondary school certificate examination in mathematics and that students performance in mathematics at the SSCE has nothing to do with gender. Also, these findings confirm (Olajide, 2006) findings that mock results are good pointer to academic performance of students in senior secondary school certificate examination in Agricultural science and further mathematics.

Table 6 has equally shown that Continuous assessment could explain or determine chemistry students academic performance in senior secondary school certificate examination particularly in WASCE. However, continuous assessment record if properly handled and managed, could provides explanatory information on variable for describing the quality of education in Ekiti State as well as Nigeria at large. It will also help to identify some problem of school children and thereby enable the educators to plan programmes that would assist in arresting such situations.

The study further found that gender is a relevant factor in its relationship with student academic performance in senior school examination certificate especially in chemistry. This support the findings of National Science Foundation (2005 and 2008). Their findings asserted that gender proves large factors in academic performance. The finding of the study is at the variance with the findings of Adesoji (1999), that students performance in senior school certificate examination has nothing to do with whether is male or female. 


\section{Conclusion}

The study revealed that the three variables proved potent at predicting academic performance in chemistry at senior secondary certificate examinations to an appreciable extent with mock results having the highest predictive capacity. Those factors directly or indirectly pointed to areas which have to be addressed in order to enhance the performance of students in chemistry. Also, students whose performance in continuous assessment and mock results are not encouraging should be hindered from registering for public examination.

Finally, if the government and other stakeholders in the educational industry could improve on the mode of assessment and organised seminars for teachers who are the curriculum implementers regularly, it is most likely that students' performance in chemistry will be highly enhanced.

\section{Recommendations}

Based on the findings of the study, the following recommendations were made: As a result of relevance of continuous assessment and mock examination as predictors of the results of students in the senior certificate examination particularly in chemistry, it would be better for present state of assessment to the statistically controlled, teachers should be trained on basic principles of developing and standardizing instruments for assessing cognitive, psychomotor and affective dimensions of learning. As these will go a long way in improving the quality of their questions.

Secondly, the government should provides enough founds for research institute and public examination bodies (NECO, WASCE and NABTEB) to carry out National Assessment of Educational Progress in Nigeria since they are the final users of continuous assessment data.

There should be periodic supervision and monitoring of the conducts of continuous assessment and mock examinations in secondary institutions so as to ensure validity and reliability of data;

Also, students whose performance in mock examination and continuous assessment are not encouraging should be hindered from registering for public examinations as WASCE and NECO;

The school authority, external examination supervisor should ensure the strict compliance with examination ethics by candidates and invigilators;

Teachers should try as much as possible to complete the chemistry syllabus and improve on the conduct of continuous assessment and mock examination.

In view of the above findings, on gender, our education, in its contents, planning and application should be gender sensitive to correct current anomalies in our culture and education. Some gender issues that must be addressed includes low status of women, son preference, female circumcision, polygamy, widowhood rites, sexual harassment girl- child abuse, rape and prostitution, increasing divorce rate, lack of proper parenting and limited access to resources education, economic and political power.

Teachers attitudes, behaviours and pedagogical strategies should be examined for gender bias. Instructional experiences should consider how to build confidence among females with regard to science achievement through constructive criticism that include positive reinforcement. In addition, the types of questions in class- tests, homework, assignment and project done in class can be designed in a way to address multiple learning styles successfully and improve science achievement among students.

Assessment used to measure science achievement at the national level as well as in classrooms should be examined for gender bias.

In essence, there is need for proper gender planning, sensitivity, training and education. This would enable women to acquire the much needed awareness and social consciousness, to embrace the doctrine of gender equality, which inform the women empowerment programme.

\section{References}

Abbas, A. B. (2007). Achieving National Economic Empowerment and development strategy through chemistry. STAN conference proceedings.

Adebayo, A. (2002). Predictive validity of the junior Secondary School Certificate Examination for Academic Performance in Senior Secondary School Certificate in Examination in Ekiti State, Nigeria. Unpublished M. Ed Thesis University of Ado Ekiti, Nigeria.

Adesoji, F. A. (1999). Mock Examination Results and students Gender as correlates of performances in the senior school certificate examinations in Mathematics. African Journal of Educational Research, 5(1), 101-107. 
Adesoji, F. A., \& Olatunbosun, S. M. (2008). student, Teacher and school Environment, factors determinants achievement in senior secondary school chemistry in Oyo State, Nigeria. The Journal of International Social Research, 1(2), 13-34.

Adeyemi, T. O. (2003). Variables Associated with the performance of students in the senior secondary certificate examinations in Ekiti State Nigeria. Being a paper presented at the senior staff seminal, Ministry of Education Ado Ekiti Nigeria.

Adeyeye, E. I., \& Ilugbusi, A. A. (2000). Correlates of the cumulative continuous assessment and the senior secondary school certificate examination in Ondo State. Benin Journal of Educational Studies, 1(1).

Agoro, A. A. (2002). Relative Effects, Institution, level of commitment and Gender on student learning outcome in Integrated Science.

Ajewole, G. A. (2005). Science and technology in secondary schools, need for manpower development. Journal of science Teachers Association of Nigeria, 40(1 and 2), 63-64.

Bajah, S. T. (1999). The challenges of sciences, Technology and Teacher Education in Nigeria beyond the year 2000. African Journal of Education, 9(1).

Ishaya, I. B. (2003). Strategies for promoting girls interest in science and technology education at the junior secondary school: the role of the school. International Journal of children in science and technology.

Jimoh, A. T. (2001). The place of women education in the development of science, mathematics and technology. 42 Annual conference Proceeding of Science Teacher Association of Niger. pp. 170-173.

National Science Foundation. (2008). Science and Engineering Indicators 2008. Retrieved from http://www.nsf. Gov/statistics/semd 08/cokoi.htm

Ogunleye, B. O. (2002). Evaluation of the environmental aspect of the senior secondary school chemistry curriculum in Ibadan. Unpublished Ph. D Thesis, University of Ibadan, Ibadan.

Ojerinde, A. (2004). Examination Malpractice in Nigerian Educational system: The NECO Annual Faculty of Education Lecture delivered at O. A. U.

Olagunju, A. M., Adesoji, F. A. Iroegbu, T. O., \& Ige, T. A. (2003). In Bamisaye, O. A., Nwazuoke, I. A., \& Okediran, A. (Eds.), Innovation in science teaching for the new millennium.

Olajide, T. O. (2006). Mock school Examination as an Indicator of performance in WAEC/GCE O/L Examinations. Unpublished Ph. D Dissertation, University of Jos, Jos. Nigeria.

Oloruntegbe, K. O. (2000). Effects of teachers sensitization on students acquisition of science process skills and attitude. Unpublished Ph. D Thesis, University of Benin.

Zuru, A. A. (2009). An address by ICCON president on the occasion of the fourth induction ceremony of the institutes of chartered chemists of Nigeria at Oranmiyan Hall, Lagos Airport Hotel, Ikeja, Lagos.

\section{Copyrights}

Copyright for this article is retained by the author(s), with first publication rights granted to the journal.

This is an open-access article distributed under the terms and conditions of the Creative Commons Attribution license (http://creativecommons.org/licenses/by/3.0/). 